\title{
A potential new data source for assessing the impacts of health reform: Evaluating the Gallup- Healthways Well-Being Index
}

\section{Citation}

Skopec, Laura, Thomas Musco, and Benjamin D. Sommers. 2014. "A Potential New Data Source for Assessing the Impacts of Health Reform: Evaluating the Gallup-Healthways Well-Being Index." Healthcare 2 (2) (July): 113-120. doi:10.1016/j.hjdsi.2014.03.001.

\section{Published Version}

doi:10.1016/j.hjdsi.2014.03.001

\section{Permanent link}

http://nrs.harvard.edu/urn-3:HUL.InstRepos:14008378

\section{Terms of Use}

This article was downloaded from Harvard University's DASH repository, and is made available under the terms and conditions applicable to Other Posted Material, as set forth at http:// nrs.harvard.edu/urn-3:HUL.InstRepos:dash.current.terms-of-use\#LAA

\section{Share Your Story}

The Harvard community has made this article openly available.

Please share how this access benefits you. Submit a story.

\section{Accessibility}




\title{
A Potential New Data Source for Assessing the Impacts of Health Reform: Evaluating the Gallup-Healthways Well-Being Index
}

\author{
Laura Skopec, M.S., ${ }^{\text {a }}$ Thomas Musco, ${ }^{b}$ B.B.A., and Benjamin D. Sommers, ${ }^{\mathrm{c}}$ M.D., Ph.D.
}

a-Formerly:

Program Analyst

Office of the Assistant Secretary for Planning and Evaluation

U.S. Department of Health and Human Services

Current Affiliation:

American Cancer Society Cancer Action Network

Email: laura.skopec@cancer.org

b - Program Analyst

Office of the Assistant Secretary for Planning and Evaluation

U.S. Department of Health and Human Services

Email: thomas.musco@hhs.gov

c - CORRESPONDING AUTHOR

Assistant Professor of Health Policy \& Economics

Harvard School of Public Health / Brigham \& Women's Hospital

677 Huntington Ave, Kresge Room 406

Boston, MA 02115

(617) 432-3271

bsommers@hsph.harvard.edu

$A N D$

Senior Advisor, Office of Health Policy

Office of the Assistant Secretary for Planning and Evaluation

U.S. Department of Health and Human Services

\section{Disclosure / Acknowledgments:}

The authors have no conflicts of interest. The findings and conclusions in this paper are those of the authors and do not necessarily represent the views of the Department of Health and Human Services (HHS). Ms. Skopec was employed at HHS during the completion of this research. She has since taken a new position at the American Cancer Society Cancer Action Network; this paper in no way represents the views of the American Cancer Society. A preliminary version of this paper was presented at the AcademyHealth Annual Research Meeting on June 25, 2013 in Baltimore, Maryland. The Gallup Organization provided data for this analysis under contract, but was not involved in the design or conduct of the study. Gallup reviewed the manuscript to provide assistance on describing the technical features of the survey design, but played no role in drafting the manuscript, describing the survey's strengths and limitations, interpreting data, or approving the final manuscript. Neither HHS nor the authors received any funding from the Gallup Organization. 


\section{A Potential New Data Source for Assessing the Impacts of Health Reform: Evaluating the Gallup-Healthways Well-Being Index}

Background: Existing national health-related surveys take several months or years to become available. The Affordable Care Act will bring rapid changes to the health care system in 2014 . We analyzed the Gallup-Healthways' Well-Being Index (WBI) in order to assess its ability to provide real-time estimates of the impact of the ACA on key health-related outcomes.

Methods: We compared the Gallup-Healthways WBI to established surveys on demographics, health insurance, access to care, and health. Data sources were the Gallup-Healthways WBI, the Current Population Survey, the American Community Survey, the Medical Expenditure Panel Survey, the National Health Interview Survey, and the Behavioral Risk Factor Surveillance System. Demographic measures included age, race/ethnicity, education, and income. Insurance outcomes were coverage rates by type, state, and year. Access measures included having a usual source of care and experiencing cost-related delays in care. Health measures were self-reported health and history of specific diagnoses.

Results: Most differences across surveys were statistically significant $(\mathrm{p}<0.05)$ due to large sample sizes, so our analysis focused on the absolute magnitude of differences. The GallupHealthways WBI post-weighted sample was similar in age, race/ethnicity, and education to other surveys, though the Gallup-Healthways WBI sample is slightly older, has fewer minorities, and is more highly educated than in other national surveys. In addition, income was more frequently missing. The Gallup-Healthways WBI produced similar national, state, and time-trend estimates on uninsured rates, but far lower rates of public coverage. Access to care and health status were similar in the Gallup-Healthways WBI and other surveys.

Conclusions: The Gallup-Healthways WBI is a valuable complement to existing data sources for health services research. The Gallup-Healthways WBI estimates for uninsured rates and access to care were similar to established national surveys and may allow for rapid estimates of the ACA's impact on the uninsured in 2014. Estimates of insurance type are less comparable, particularly for public coverage, which likely limits the utility of the Gallup-Healthways WBI for analyzing changes in particular types of coverage.

Key Words: data sources, health insurance, access to care, survey, health policy 


\section{INTRODUCTION}

The Gallup-Healthways Well-Being Index is part of the Gallup Corporation's daily tracking poll, featuring questions on health insurance, health status, and access to care. The Well-Being Index (WBI), created in 2008, represents a potentially valuable new data source for health and health care research. It has been used for policy analysis on the expansion of insurance coverage to young adults under the Affordable Care Act (ACA), ${ }^{1}$ and state-level variation in uninsurance rates. ${ }^{2}$ Survey data in general is used extensively in health services research, particularly for studies of large coverage changes and insurance participation rates. ${ }^{3-6}$ With major insurance expansions under the ACA set to begin in $2014^{7}$ and ongoing major changes in health care delivery, the availability of rapid and accurate estimates on coverage and access to care will be critical. While administrative data can often provide rapid and accurate estimates of how many individuals have enrolled in or utilized a particular program, survey data provides an important cross-sectional view of overall coverage rates in the population, across the range of government programs and private plans. While the Gallup-Healthways WBI may be capable of fulfilling an important research role in the coming years, its comparability to wellestablished national surveys is unknown and is a pre-requisite to its broader use for research.

The Gallup-Healthways WBI is a daily telephone interview conducted throughout the year, interviewing 500 adults each day from all 50 states and the District of Columbia (1000 per day before 2013). Interviews are conducted with respondents on listed landline telephones and random-digit-dial cellular phones, with interviews in Spanish as needed. Gallup recently increased the proportion of cell phone participants based on shifts in communication behavior. ${ }^{8}$ Samples are weighted to targets for region, age, gender, race, ethnicity, education, number of adults, and telephone status percent based on the Current Population Survey (CPS). Data can be 
summarized at the state, congressional district, and Metropolitan Statistical Area (MSA) levels. Additional methodological detail is provided in the Appendix.

The objectives of this study are to describe the Gallup-Healthways WBI and compare its estimates of several health policy measures to other established national surveys.

\section{METHODS}

\subsection{Data}

We use data from the 2008-2011 Gallup-Healthways WBI. We compared the WBI to the following national surveys: the Current Population Survey (CPS) and the American Community Survey (ACS), conducted by the Census Bureau; the Medical Expenditure Panel Survey (MEPS) Household Component, conducted by the Agency for Healthcare Research and Quality; the National Health Interview Survey (NHIS), conducted by the National Center for Health Statistics; and the Behavioral Risk Factor Surveillance System (BRFSS), conducted by 50 states and the District of Columbia in cooperation with the Centers for Disease Control and Prevention. We note that other national surveys, such as the National Health and Nutrition Examination Survey (NHANES), also provide estimates of health insurance coverage and access to care. However, we have limited our comparisons to the largest national surveys, with a particular emphasis on those surveys that can produce state-level estimates or that have been used most frequently to analyze major changes in insurance coverage. ${ }^{9-12}$ For each survey, we used data from 2008 through the most recently available year at the time of our analysis, which differed by survey (2011 for ACS, CPS, BRFSS, and NHIS; 2009 for MEPS). Gallup-Healthways WBI data were obtained under contract with the Gallup Organization. The remaining data sources are publicly available at no cost. 


\subsection{Statistical Analysis}

Our analytical approach was largely descriptive. We compared the following demographic characteristics of the Gallup-Healthways WBI adult sample to recent estimates (calendar year 2010) from the CPS, ACS, and NHIS: age, race/ethnicity, children in the household, education, and income. For each outcome, we did bivariate comparisons between Gallup-Healthways WBI estimates and the government surveys using chi square tests for binary outcomes and t-tests for continuous outcomes. For context, we also conducted bivariate comparisons between estimates from the government surveys. We categorized each outcome as similarly as possible to its counterpart across surveys. For instance, household income in the Gallup-Healthways WBI is reported in discrete categories, so in comparing to other surveys we used the same income cutoffs. We limited the sample in all analyses to adults 18 and over, to be consistent with the Gallup-Healthways WBI.

We compared the following health insurance outcomes in Gallup-Healthways WBI to the CPS, ACS, and NHIS: any health insurance by year (2008-2011) and by state (2010), and by type of coverage (employer-sponsored insurance [ESI], military coverage, Medicare, Medicaid, 'something else,' and 'do not know/refused/missing'). The Gallup-Healthways WBI only allows each person to select one type of coverage, unlike the other surveys we examined. For this reason, we compared Gallup-Healthways WBI data to estimates from CPS, ACS, and NHIS in two different forms. First, we examined CPS, ACS, and NHIS estimates as collected in the survey, allowing for multiple types of coverage. Then, we compared the Gallup-Healthways WBI to these sources after imposing a health insurance hierarchy, in which each person was assigned a primary form of coverage. For adults 18-64, the hierarchy was: 1) ESI, 2) 
Medicaid/CHIP, 3) Medicare, 4) Military coverage, 5) Other or Non-Group Coverage, 6)

Uninsured. For elderly adults, Medicare was first in the hierarchy, with the remaining order unchanged. We also tested an alternative hierarchy, in which ESI was placed before Medicare for adults over age 65. For coverage rates by state and over time, we used Pearson correlation coefficients to describe the relationship between the Gallup-Healthways WBI estimates and those in other data sets.

We compared access measures and health status using the NHIS, MEPS, and BRFSS. Outcomes were having a personal doctor / usual source of care, cost-related barriers to care, selfreported health, and history of specific disease diagnoses.

Precise wording for the Gallup-Healthways WBI items are presented in the Appendix. All analyses were conducted using STATA 12.0, accounting for the specific survey design of each data source and using appropriate weights. In the Gallup-Healthways WBI, this included using separate weights, provided by Gallup-Healthways, for state and national estimates; national weights are available on a daily basis, but state-specific weights are only calculated by Gallup-Healthways every 6 months.

\section{RESULTS}

Table 1 presents key features of each survey. Notable strengths of the GallupHealthways WBI are that it covers more health-related domains than Census surveys; it has a large sample $(355,000)$ compared to the most detailed health surveys (NHIS and MEPS, which survey approximately 100,000 and 35,000 individuals, respectively); it supports state-level analyses; and it has a very rapid turnaround time with data available for analysis within one week of collection (though state-level weights are only calculated twice annually). The survey's limitations for research purposes include a lack of information on children, lack of historical data 
prior to 2008, more limited income data, and availability through direct purchase from GallupHealthways. Additionally, the Gallup-Healthways WBI asks respondents to report detailed insurance and health-related information only about themselves, unlike most national surveys, which also collect information about other members of the household.

The Gallup-Healthways WBI describes its purpose as to provide "statistics on the state of well-being in the United States." But as a commercial product designed to provide real-time data to its customers, it differs in important ways from the government surveys that are designed primarily for public research efforts. For instance, Gallup-Healthways WBI's frequent methodological and question changes introduce a level of uncertainty not generally encountered in government surveys, and the reasons for methodological changes are not always made public. In this vein, the daily WBI sample was cut in half as of January 2013 to enable Gallup to move resources towards expanding their international polling; the net impact was a significant reduction in statistical power and precision compared to the first four years of the survey. While government surveys also change over time - in particular some government surveys are introducing question changes to better detect the coverage and access effects of the Affordable Care Act - these changes tend to be approached with caution and attention to minimizing breaks in trend. In addition to WBI's unpredictability, the most concerning methodological limitation of the survey is its response rate of $11 \%$. While this rate is similar to that of other telephone surveys, it is far below those of the government surveys (which range from $50 \%-98 \%$ ).

Table 2 compares demographics from the surveys. Essentially all the demographic findings differed statistically between the WBI and other surveys, in some cases even for differences that were less than 0.5 percentage points, due the extremely large samples for pooled analyses (ranging from approximately 400,000 for the Gallup-Healthways WBI vs. MEPS 
comparisons, to nearly 3.5 million for Gallup-Healthways WBI comparisons to the ACS). For the same reason, the government surveys have statistically significant differences from one another on numerous outcomes, including income, education, insurance coverage types, health status, and access to care. Given these concerns, our discussion below focuses on the magnitude of the differences in estimates that may be relevant for policy purposes, rather than statistical significance.

As shown in Table 2, the Gallup-Healthway WBI sample had fewer adults ages 18-34 (25.3\% total, versus $30.8 \%$ in CPS, $30.5 \%$ in ACS, and $30.8 \%$ in NHIS) and slightly more elderly adults (10.8\% between the ages of $65-74$ and $8.3 \%$ who are 75 or older, compared to 9.2$9.3 \%$ and $7.6-7.9 \%$ in the other surveys). Men accounted for $48.2-48.6 \%$ of the sample across the four surveys. Though the Gallup-Healthways WBI has little information on children, it does ask whether a child lives in the household; on this measure, the Gallup-Healthways WBI matched ACS, CPS, and NHIS closely, each reporting that $36 \%$ to $38 \%$ of households had children under 18.

The Gallup-Healthways WBI sample had a roughly 5-percentage-point larger share of White non-Latinos and 3-percentage-point smaller Latino population, compared to Census Surveys. The Gallup-Healthways WBI had a 3-percentage-point lower share of Asians. Educational attainment was slightly higher in the Gallup-Healthways WBI sample, with 30.5\% having a four-year college degree compared to $27.8 \%$ in CPS, $25.4 \%$ in ACS, and $26.8 \%$ in NHIS.

In terms of income, $22 \%$ of the Gallup-Healthways WBI survey participants did not respond to the income question, although CPS and ACS have imputed income in their public use files, and we used the NHIS imputed income files, creating the false appearance that no adults 
have unknown incomes in those surveys when in fact the imputation rates for those surveys is quite similar to that in the WBI. For example, between $24-33 \%$ of adults in the NHIS had unknown incomes in survey years 2007 to 2010 , and $22.4 \%$ of ACS respondents had some or all income imputed in 2010.

To test for any underlying pattern in the missing data for income in the GallupHealthways WBI, we conducted an imputation for missing income values using multivariate regression. First, we translated the Gallup-Healthways WBI categories into a linear income variable by taking the midpoint of each income bucket. Then, we modeled income as a function of age, race/ethnicity, sex, state of residence, family size, marital status, self-reported health status, employment, and health insurance. Overall, those with missing income data had an imputed average income of $\$ 51,000$, compared to $\$ 55,000$ for those reporting their household income. Imputed income values also were more clustered in the middle of the income distribution, with fewer households having income under $\$ 24,000$, and fewer having income higher than $\$ 90,000$. Putting these imputed values together with the observed values (Appendix Table 1), the overall impact is that the Gallup-Healthways WBI has a similar share of lowincome adults but more adults in the middle income range $(\$ 24,000-\$ 60,000)$ and fewer higherincome adults (above $\$ 90,000$ ) than the government surveys.

Figure 1 shows the time trend in the estimates of non-elderly adults without health insurance for 2008-2011. The uninsured rate for the Gallup-Healthways WBI was approximately 2 percentage points lower than in the other surveys, but followed a fairly similar trend over time; though in 2011, the gap between the Gallup-Healthways WBI and the other surveys narrowed. Pairwise correlation coefficients for the annual uninsured rate between the Gallup-Healthways WBI and other surveys were high: 0.87 with the CPS, 0.85 with the ACS, 
0.82 with the NHIS, and 0.63 with the BRFSS. These correlation coefficients were similar but slightly smaller than the correlations among most of the established surveys: 0.85 for ACS and CPS, 0.93 for NHIS and CPS, and 0.97 for NHIS and ACS. However, the BRFSS, which underwent a sample redesign including more cell phones in 2011, was an outlier, with correlation coefficients ranging from 0.16 to 0.34 with respect to the other government surveys.

Comparisons of state-level estimates of uninsured rates were even more closely matched across data sources, with correlation coefficients of 0.95 for Gallup-Healthways WBI and ACS, and 0.89 for Gallup-Healthways WBI and CPS (compared to 0.93 for ACS and CPS). Appendix Figures 1 and 2 present scatterplots of state-level estimates of uninsured rates using GallupHealthways WBI data versus the ACS and CPS, respectively. The observed relationship between the data sources indicates very close overlap in the relative ranking of uninsured rates across states.

Table 3 shows the type of coverage for adults 18-64 and for adults 65 and over. Panel A reports estimates from the surveys allowing for multiple types of coverage (CPS, ACS, and NHIS). Among adults 18-64, ESI rates were 6-8 percentage points lower in Gallup-Healthways WBI than other surveys (52.3\% versus 58.2-60.1\%). Military coverage rates were similar. Medicare rates were slightly higher, and Medicaid rates were only half as large in GallupHealthways WBI compared to other surveys (4.9\% versus 9.2-10.6\%). State-level Medicaid estimates are moderately correlated for Gallup-Healthways WBI compared to other national surveys, but are still fairly noisy and inconsistent (see Appendix Figures 3 and 4): correlation coefficients were 0.47 for Gallup-Healthways and the CPS, and 0.59 for Gallup-Healthways WBI and the ACS, respectively. For comparison, the correlation coefficient for state-level Medicaid coverage in the ACS and CPS is 0.94. 
Rates of "Other Sources" of health insurance were higher in Gallup-Healthways WBI than in the government surveys, though the values of non-group coverage in the other surveys already varies widely, with the ACS a known outlier. ${ }^{13}$ Among the elderly, rates of Medicare were much lower in Gallup-Healthways WBI (64.7\%, as opposed to over $90 \%$ in other surveys), with $13 \%$ reporting ESI, $8 \%$ other, and 5\% unknown. Many elderly adults reported multiple forms of coverage in the CPS, ACS, and NHIS. When we implemented a hierarchy for the government surveys placing ESI before Medicare for elderly adults, we found more similar Medicare rates between the Gallup-Healthways WBI and CPS and ACS (64.7\% for GallupHealthways WBI, $66.1 \%$ for CPS, $62.4 \%$ for ACS). However, the Gallup-Healthways WBI still underestimates ESI for the elderly relative to the other government surveys, even using the alternative hierarchy (13\% for Gallup-Healthways WBI, 31.4\% for CPS, and 36.3\% for ACS).

Panel B reports estimates using a health insurance hierarchy to assign each person a primary form of coverage. This produces somewhat more comparable estimates between Gallup-Healthways WBI and other surveys, though large differences persist. Among non-elderly adults, Medicaid rates in Gallup-Healthways WBI remained roughly half of those in the other surveys, though the Gallup-Healthways WBI Medicare rate exceeded other surveys. The "Other Sources" category in Gallup-Healthways WBI remained nearly twice as large as the non-group share in the CPS, ACS, and NHIS. Among the elderly, the insurance hierarchy led to more similar results among the surveys for non-Medicare forms of coverage, but overall, Medicare rates in Gallup-Healthways WBI remain much lower than in other surveys. 3.7\% of non-elderly adults in Gallup-Healthways WBI reported having insurance but did not know or refused to provide their coverage type. Though Table 3 appears to indicate no missing values for health insurance for the CPS and ACS, insurance values are imputed for these surveys. In 2010, 
between $5.2 \%$ and $8.5 \%$ of health insurance type values were imputed in the ACS, depending on insurance type.

Table 4 shows results for measures of access to care (Panel A) and health status (Panel B). Roughly $80 \%$ of adults in Gallup-Healthways WBI, NHIS, and BRFSS reported having a usual source of care or personal doctor. Cost-related barriers to care (with different question wording) were present among $18.6 \%$ of Gallup-Healthways WBI respondents, $17.6 \%$ of NHIS respondents, $14.9 \%$ of BRFSS respondents, and $9.0 \%$ in the MEPS. Gallup-Healthways WBI produces fairly similar estimates on self-reported health, with all surveys showing slightly over half of adults in "excellent" or "very good" health. However, Gallup-Healthways WBI has a 5-8 percentage point higher share of adults in fair or poor health status than other surveys. In terms of specific medical conditions, Gallup-Healthways WBI's results were fairly comparable to the other sources, with estimates for each specific disease generally within 2-4 percentage points of the other surveys.

\section{DISCUSSION}

\subsection{Key Findings}

In this exploratory analysis of the Gallup-Healthways WBI, we found that the survey provides reasonably similar data when compared to established national surveys on several important health-related measures, including population demographics, the overall uninsured rate at the national and state levels, trends in coverage over time, access to care, and self-reported health status, though some important differences are evident and would need to be acknowledged in any future research using the Gallup-Healthways WBI: the Gallup sample is slightly older, has fewer minorities, and is more highly educated than samples in other national surveys. In all of 
these results, we focus on the absolute magnitude of differences in estimates, as we feel that statistical significance has little relevance in very large samples such as these - evident in the fact that the gold-standard government surveys themselves revealed numerous statistically significant differences from one another in our analyses.

Several key features of the Gallup-Healthways WBI make it appealing for research: it has a large enough sample to support state-level estimates on an annual basis for nearly all 50 states (though with a significant loss of precision due to the $50 \%$ reduction in health-related sample size in 2013); it has a very rapid turnaround time, enabling data analysis to occur literally within days of data collection; and it has questions across multiple domains of health care. The CPS and ACS have limited or no information on health care utilization, while MEPS and NHIS do provide considerable data on this measure, but with smaller samples and slower turnaround times than Gallup-Healthways WBI. These strengths of the Gallup-Healthways WBI may help fill some of the data gaps that others have identified in the current national survey options for health services research. ${ }^{14}$

The demographic differences in the Gallup-Healthways WBI discussed above may particularly have an effect on measures of insurance type, as Gallup-Healthways may not be reaching younger, minority, lower education populations as effectively. Some of these differences may be an artifact of Gallup-Healthways WBI's weighting to telephone households, not the entire adult population. But overall differences were generally small, on the order of several percentage points. Also, the Gallup-Healthways WBI questions on race and ethnicity differed from other surveys prior to 2011. Gallup-Healthways WBI did not begin recording separate results for American Indians / Alaska Natives, Native Hawaiians, or Pacific Islanders until April 2011, meaning that these groups are included in the "Other" category prior to that 
year. Also beginning in 2011, respondents were allowed to select more than one race, whereas previously they had to choose just one. Finally, Gallup-Healthways WBI is conducted only in English and Spanish, which may explain the lower prevalence of Asians.

Gallup-Healthways WBI's income data is also collected differently from other surveys. Instead of collecting specific dollar values for different types of income for each person, and then summing across household members, Gallup-Healthways WBI simply asks the respondent to describe "monthly household income" and records the response in 10 discrete categories. This precludes making precise estimates of a family's poverty status and/or income related to key program eligibility thresholds, such as the ACA's Medicaid eligibility expansion up to $138 \%$ of the Federal Poverty Level. In this regard, Gallup-Healthways WBI data provide limited income information analogous to that collected in the BRFSS, which is one disadvantage compared to the Census surveys, NHIS, and MEPS. Nonetheless, our analyses suggest that the GallupHealthways WBI captures a similar share of low-income households as other surveys, and in fact, the main income differences were primarily the lower prevalence of high-income households in Gallup-Healthways WBI and a higher prevalence of respondents refusing to provide income data. After income imputation, the Gallup-Healthways WBI has a similar share of low-income adults but more adults in the middle income range $(\$ 24,000-\$ 60,000)$ and fewer higher-income adults (above $\$ 90,000$ ) than the government surveys. There is some evidence that omnibus income questions, such as those used by Gallup-Healthways, produce lower estimates than the more detailed series of questions in the CPS. ${ }^{15}$

In terms of health insurance, results were mixed. The government surveys differ in how questions about health insurance are asked, but despite that, produce similar estimates of the uninsured rate - other than the BRFSS. Gallup-Healthways WBI reports an uninsured rate 
among non-elderly adults approximately 2 percentage points below that of the other surveys, a small but significant difference. Despite this difference in baseline uninsured rates, GallupHealthways WBI tracked fairly well with changes estimated in other surveys over time and across states. Given these findings and the near-instantaneous availability of Gallup-Healthways WBI results after data collection, the WBI could be particularly useful as an early indicator of the effectiveness of major coverage expansions planned for January 2014 under the ACA by providing near-instantaneous data on changes in uninsured rates and access to care measures.

However, the Gallup-Healthways WBI measures for insurance type produced substantially different results from the other surveys. The discrepancies likely relate to the insurance question wording in the Gallup-Healthways WBI, which does not allow multiple types of coverage. The Gallup-Healthways WBI asks respondents to select only their primary insurance type from this list: employer or union, Medicare, Medicaid, military or Veteran's coverage, or something else. In contrast, the CPS, ACS, and NHIS allow respondents to select multiple insurance sources, and the CPS and NHIS also prompt respondents with state-specific names for Medicaid and CHIP. The Gallup-Healthways WBI question wording likely contributes to the low prevalence of Medicare among the elderly in Gallup-Healthways WBI compared to other surveys, as respondents with both Medicare and ESI or Medicaid must report only one type of coverage. In addition, the lack of state-specific Medicaid prompts likely leads to underreporting of Medicaid coverage and overreporting of "something else," as does the prevalence of Medicaid managed care plans. Finally, it is possible that confusion about the differences between Medicare and Medicaid coverage on the part of Gallup-Healthways WBI participants, without any further prompts to help them distinguish the two, or confusion about how to report Medicare or Medicaid managed care plans, may further contribute to Gallup- 
Healthways WBI's lower estimates of public coverage. Options to improve the type-of-coverage estimates would be for Gallup-Healthways WBI to change its existing insurance questions to allow for more than one type of coverage and to use state-specific prompts for Medicaid.

For access to care and health status, the Gallup-Healthways WBI provides estimates generally in the range of other surveys, though Gallup-Healthways WBI had a slightly higher proportion of respondents in fair or poor health. It should be noted that, unlike population demographics and insurance coverage, which are fairly similar across the Census Surveys and NHIS, measures of access and health are much more variable across existing data sources. This is likely due to greater variability in question phrasing and more subjectivity in interpreting questions in these domains. Against this backdrop, the Gallup-Healthways WBI results for percentage of adults with a usual source of care, cost-related barriers to medical care, and selfreported health (in general and by specific conditions) match up well with the other surveys.

\subsection{Limitations}

Like the Gallup-Healthways WBI, our analysis has strengths and limitations. In the interest of introducing this dataset to the research community, we analyzed a wide range of outcomes at a broad descriptive level. An alternative approach would be to take a small number of outcomes (such as insurance coverage type) and conduct a more intensive exploration, examining patterns for various subgroups and comparing trends over time within those groups. Future research along those lines for key policy outcomes would be worthwhile.

Another issue for future exploration is whether the differences we observed between Gallup-Healthways WBI and other sources could be mitigated with various statistical techniques. Options would include using imputation for missing values, and potential re-weighting to more 
closely match national estimates. However, the latter approach is only possible using older data from other sources since new data from Gallup-Healthways WBI will be available months before the other surveys release their findings. Given that one of the main advantages of the GallupHealthways WBI data is its rapid release, waiting for corroborating results from other surveys may not be practical.

\subsection{Conclusion}

The Gallup-Healthways Well-Being Index is a valuable but imperfect new data option for health policy research. In the areas of population demographics, overall rates of health insurance coverage, access to care, and self-reported health status, Gallup-Healthways WBI data are reasonably similar to well-established and validated national surveys. Estimates of type of insurance are less comparable, particularly for public coverage, which could lead to improper estimation of effects of particular policies or trends on coverage type. Gallup-Healthways WBI data seem particularly well-suited for real-time analyses of certain changes in health care trends that do not require distinguishing between different types of insurance coverage, such as whether the ACA had reduced the number of uninsured adults in the U.S., similar impacts of state expansions, and the impact of these changes on access to care. However, the lack of historical data or information on children, the lower response rate compared to in-person interview surveys, and its availability only under direct purchase from Gallup-Healthways WBI are important limitations to its use. Overall, the Gallup-Healthways WBI can fill important needs as a complement to but not a replacement for the well-established and highly rigorous government surveys, which likely will remain the workhorses for health services research in the years to come. 


\section{REFERENCES}

1. In U.S., significantly fewer 18- to 25-year-olds uninsured. 2011. (Accessed at http://www.gallup.com/poll/149558/Significantly-Fewer-Year-Olds-Uninsured.aspx.)

2. Texas Widens Gap Over Other States in Percentage Uninsured. 2012. (Accessed at http://www.gallup.com/poll/153053/texas-widens-gap-states-percentage-uninsured.aspx.)

3. Kenney GM, Lynch V, Haley J, Huntress M. Variation in Medicaid eligibility and participation among adults: implications for the Affordable Care Act. Inquiry 2012;49:231-53.

4. Sommers BD, Baicker K, Epstein AM. Mortality and Access to Care among Adults after State Medicaid Expansions. N Engl J Med 2012.

5. Sommers BD, Kronick R. The Affordable Care Act and insurance coverage for young adults. Jama 2012;307:913-4.

6. Hamersma S, Kim M. Participation and crowd out: Assessing the effects of parental Medicaid expansions. J Health Econ 2013;32:160-71.

7. Elmendorf DW. Estimates for the Insurance Coverage Provisions of the Affordable Care Act Updated for the Recent Supreme Court Decision. Washington DC: Congressional Budget Office; 2012.

8. Obama approval rating gets a boost after Gallup tweaks its polling methodology. 2012. (Accessed at http://thehill.com/homenews/campaign/261485-obama-gets-a-boost-after-galluptweaks-polling-methodology.)

9. Currie J, Gruber J. Health insurance eligibility, utilization of medical care and child health. Quarterly Journal of Economics 1996;111:431-66.

10. Sommers BD, Buchmueller T, Decker SL, Carey C, Kronick R. The Affordable Care Act has led to significant gains in health insurance and access to care for young adults. Health Aff (Millwood) 2013;32:165-74.

11. Pande AH, Ross-Degnan D, Zaslavsky AM, Salomon JA. Effects of healthcare reforms on coverage, access, and disparities: quasi-experimental analysis of evidence from Massachusetts. Am J Prev Med 2011;41:1-8.

12. Kolstad JT, Kowalski AE. The Impact of Health Care Reform on Hospital and Preventive Care: Evidence from Massachusetts. Journal of Public Economics 2012;96:909-29.

13. Mach A, O'Hara B. Do people really have multiple health insurance plans? Estimates of Nongroup Health Insurance in the American Community Survey. Washington, D.C.: U.S.

Census Bureau; 2011.

14. Kenney G, Holahan J, Nichols L. Toward a more reliable federal survey for tracking health insurance coverage and access. Health Serv Res 2006;41:918-45.

15. Davern M, Rodin H, Beebe TJ, Call KT. The effect of income question design in health surveys on family income, poverty and eligibility estimates. Health Serv Res 2005;40:1534-52. 


\section{Table 1: Key Features of Gallup-Healthways Well-Being Index and other National Health-Related Surveys}

\begin{tabular}{|c|c|c|c|c|c|c|}
\hline $\begin{array}{l}\text { FEATURES \& } \\
\text { TOPICS } \\
\text { COVERED }\end{array}$ & $\begin{array}{c}\text { Gallup- } \\
\text { Healthways } \\
\text { Well-Being } \\
\text { Index } \\
\text { (WBI) } \\
\end{array}$ & $\begin{array}{c}\text { Current } \\
\text { Population } \\
\text { Survey } \\
\text { (CPS) }\end{array}$ & $\begin{array}{c}\text { American } \\
\text { Community } \\
\text { Survey } \\
\text { (ACS) }\end{array}$ & $\begin{array}{c}\text { National } \\
\text { Health } \\
\text { Interview } \\
\text { Survey } \\
\text { (NHIS) } \\
\end{array}$ & $\begin{array}{c}\text { Medical } \\
\text { Expenditure } \\
\text { Panel } \\
\text { Survey } \\
\text { (MEPS) } \\
\end{array}$ & $\begin{array}{c}\text { Behavioral } \\
\text { Risk Factor } \\
\text { Surveillance } \\
\text { System } \\
\text { (BRFSS) } \\
\end{array}$ \\
\hline Sponsor & Gallup & Census & Census & NCHS & AHRQ & $\mathrm{CDC} /$ States \\
\hline $\begin{array}{l}\text { Approximate } \\
\text { Sample Size }\end{array}$ & $355,000 \#$ & 200,000 & $3,000,000$ & 100,000 & 35,000 & 450,000 \\
\hline $\begin{array}{l}\text { Approximate } \\
\text { Response Rate* }\end{array}$ & $11 \%$ & $91 \%-93 \%$ & $93 \%-98 \%$ & $80 \%-90 \%$ & $63 \%-71 \%$ & $50-58 \%$ \\
\hline $\begin{array}{l}\text { Population } \\
\text { Age+ }\end{array}$ & 18 and over & $\begin{array}{c}\text { Children \& } \\
\text { Adults }\end{array}$ & $\begin{array}{c}\text { Children \& } \\
\text { Adults }\end{array}$ & $\begin{array}{c}\text { Children \& } \\
\text { Adults }\end{array}$ & $\begin{array}{c}\text { Children \& } \\
\text { Adults }\end{array}$ & 18 and over \\
\hline $\begin{array}{l}\text { Year Survey } \\
\text { Began }\end{array}$ & 2008\#\# & $1980 \S$ & 2008\#\# & 1957 & 1996 & $1994 * *$ \\
\hline $\begin{array}{l}\text { Time Lag for } \\
\text { Data Use }\end{array}$ & $<1$ week & 9 months & 9 months & 3-6 months & $1-2$ years & 6-9 months \\
\hline $\begin{array}{l}\text { Publicly- } \\
\text { Available }\end{array}$ & No & Yes & Yes† & Yes & Yes & Yes \\
\hline $\begin{array}{l}\text { State-Level } \\
\text { Estimates }\end{array}$ & Yes & Yes & Yes & Some & No & Yes \\
\hline Longitudinal & No & Limited++ & No & Limited++ & Yes & No \\
\hline Demographics & Yes & Yes & Yes & Yes & Yes & Yes \\
\hline Income & Limited & Detailed & Detailed & Detailed & Detailed & Limited \\
\hline $\begin{array}{l}\text { Health } \\
\text { Insurance }\end{array}$ & $\begin{array}{l}\text { Yes, primary } \\
\text { source only }\end{array}$ & Yes & Yes & Yes & Yes & $\begin{array}{c}\text { Insured vs. } \\
\text { uninsured only }\end{array}$ \\
\hline Access to Care & Yes & No & No & Yes & Yes & Yes \\
\hline $\begin{array}{l}\text { General Health } \\
\text { Status }\end{array}$ & Yes & Yes & No & Yes & Yes & Yes \\
\hline $\begin{array}{l}\text { Specific } \\
\text { Medical } \\
\text { Conditions }\end{array}$ & Yes & No & No & Yes & Yes & Yes \\
\hline Utilization & Limited $\dagger \dagger$ & No & No & Yes & Yes & Limited \\
\hline $\begin{array}{l}\text { Premiums \& } \\
\text { Medical } \\
\text { Spending }\end{array}$ & No & Limited & No & Limited & Yes & No \\
\hline
\end{tabular}

Notes:

NCHS $=$ National Center for Health Statistics

$\mathrm{CDC}=$ Centers for Disease Control and Prevention

\# The sample size was 355,000 for years $2008-2012$; it is approximately 177,000 for health-related questions, as of 2013.

* Response rates are from the following sources, respectively: Gallup-Healthways estimate of daily tracking poll response rate; Census estimates of average CPS response rates; ACS housing unit response rates between 2000 and 2010; NHIS household response rates between 2000 and 2010; MEPS point-in-time panel response rates between 2000 and 2009; BRFSS median state-based response rates between 2000 and 2010.

+The Gallup-Healthways WBI asks respondents only about themselves, while the other surveys ask about all members of the household. All surveys include non-citizens.

\#\# The Gallup daily tracking survey and ACS both existed prior to 2008, but did not collect health related information until that year.

$\S$ The CPS has existed since the 1950's, but only began collecting health insurance information in 1980. 
** The BRFSS began in 15 states in 1984, but did not reach national coverage in all states and the District of Columbia until 1994.

++ The CPS is generally thought of as a repeated cross-section, though roughly half of each year's sample is targeted for surveying the following year (minus attrition), and the survey may be used for 2-year longitudinal analyses. The NHIS survey is used as the sampling frame for the MEPS and through linkage with that survey can be used for longitudinal analysis.

$\dagger$ The full ACS contains approximately 7.5 million respondents. The public-use microdata sample contains a subset of 3 million individuals, with edited data to protect confidentiality.

$\dagger$ Gallup-Healthways WBI's single utilization question asks only whether a person has visited a dentist in the past 12 months. 
Table 2: Comparing Demographics in Gallup-Healthways Well-Being Index versus Government Surveys (Calendar Year 2010) $\dagger$

\begin{tabular}{|c|c|c|c|c|}
\hline Variable & $\begin{array}{c}\text { Gallup- } \\
\text { Healthways Well- } \\
\text { Being Index } \\
\text { (WBI), 2010 }\end{array}$ & $\begin{array}{c}\text { (a) } \\
\text { Current } \\
\text { Population Survey } \\
\text { (CPS), 2010 } \\
\end{array}$ & $\begin{array}{c}\text { (b) } \\
\text { American } \\
\text { Community Survey } \\
(\text { ACS }), 2010\end{array}$ & $\begin{array}{c}\text { (c) } \\
\text { National Health } \\
\text { Interview Survey } \\
\text { (NHIS), 2010 }\end{array}$ \\
\hline \multicolumn{5}{|l|}{$\underline{\text { Age }}$} \\
\hline - Mean & $48.2^{a b c}$ & $46.2^{b}$ & $46.4^{\mathrm{a}}$ & 46.2 \\
\hline$-18-25, \%$ & $12.0 \%{ }^{a b c}$ & $14.7 \%$ & $15.0 \%$ & $14.8 \%$ \\
\hline$-26-34, \%$ & $13.3 \%{ }^{a b c}$ & $16.1 \%^{\mathrm{b}}$ & $15.5 \%^{\mathrm{ac}}$ & $16.0 \%^{\mathrm{b}}$ \\
\hline$-35-44, \%$ & $16.9 \%{ }^{a b c}$ & $17.2 \%^{b}$ & $17.6 \%{ }^{\mathrm{a}}$ & $17.4 \%$ \\
\hline$-45-54, \%$ & $20.2 \%{ }^{a b c}$ & $19.0 \%$ & $19.1 \%$ & $19.3 \%$ \\
\hline$-55-64, \%$ & $17.3 \%{ }^{a b c}$ & $16.0 \%^{\mathrm{b}}$ & $15.6 \%{ }^{\mathrm{a}}$ & $15.6 \%$ \\
\hline$-65-74, \%$ & $10.8 \%{ }^{a b c}$ & $9.3 \%$ & $9.3 \%$ & $9.2 \%$ \\
\hline - 75 or older, $\%$ & $8.3 \%^{a b c}$ & $7.7 \%^{b}$ & $7.9 \%^{\mathrm{a}}$ & $7.6 \%$ \\
\hline - Refused / Missing & $1.2 \%{ }^{\mathrm{abc}}$ & $0.0 \%$ & $0.0 \%$ & $0.0 \%$ \\
\hline Male & $48.2 \%{ }^{\mathrm{ab}}$ & $48.6 \%$ & $48.5 \%$ & $48.3 \%$ \\
\hline \multicolumn{5}{|l|}{ Race/Ethnicity } \\
\hline - White, non-Latino & $71.6 \%{ }^{a b c}$ & $67.8 \%{ }^{\mathrm{b}}$ & $66.9 \%^{\mathrm{ac}}$ & $68.5 \%^{\mathrm{b}}$ \\
\hline - Latino & $11.4 \%{ }^{a b c}$ & $14.0 \%$ & $14.3 \%$ & $14.0 \%$ \\
\hline - Black, non-Latino & $10.0 \%{ }^{a b c}$ & $11.5 \%$ & $11.7 \%$ & $12.0 \%$ \\
\hline - Asian, non-Latino & $1.5 \%{ }^{a b c}$ & $4.7 \%$ & $4.8 \%$ & $4.7 \%$ \\
\hline - Other & $4.3 \%$ abc & $2.0 \%{ }^{b c}$ & $2.3 \%^{a c}$ & $0.9 \%{ }^{a b}$ \\
\hline $\begin{array}{l}\text { - Don't know/ Refused / } \\
\text { Missing }\end{array}$ & $1.2 \%{ }^{a b c}$ & $0.0 \%$ & $0.0 \%$ & $0.0 \%$ \\
\hline \multicolumn{5}{|l|}{ Education } \\
\hline $\begin{array}{l}\text { - Less than High School } \\
\text { Degree }\end{array}$ & $11.2 \%{ }^{a b c}$ & $13.3 \%{ }^{\mathrm{bc}}$ & $14.7 \%^{\mathrm{a}}$ & $14.3 \%^{a}$ \\
\hline - High School Grad or GED & $29.0 \%{ }^{a b c}$ & $30.4 \%{ }^{b c}$ & $28.6 \%^{\mathrm{ac}}$ & $27.9 \%{ }^{a b}$ \\
\hline $\begin{array}{l}\text { - Some College or } \\
\text { Associate's Degree }\end{array}$ & $28.2 \%{ }^{b c}$ & $28.5 \%{ }^{b c}$ & $31.0 \%{ }^{\mathrm{ac}}$ & $29.3 \%{ }^{a b}$ \\
\hline $\begin{array}{l}\text { - College Graduate } \\
\text { (Bachelor's Degree) }\end{array}$ & $30.5 \%{ }^{a b c}$ & $27.8 \%{ }^{b c}$ & $25.7 \%^{\mathrm{ac}}$ & $26.8 \%{ }^{a b}$ \\
\hline $\begin{array}{l}\text { - Don't know/ Refused / } \\
\text { Missing }\end{array}$ & $1.1 \%{ }^{\mathrm{abc}}$ & $0.0 \%^{\mathrm{c}}$ & $0.0 \%^{\mathrm{c}}$ & $1.7 \%^{a b}$ \\
\hline Households with Children & $37.1 \%{ }^{b c}$ & $37.1 \%^{b}$ & $36.2 \%{ }^{\mathrm{ac}}$ & $38.0 \%^{\mathrm{b}}$ \\
\hline \multicolumn{5}{|l|}{ Annual Household Income } \\
\hline$<\$ 6000$ & $2.8 \%{ }^{b c}$ & $2.9 \%{ }^{b c}$ & $4.6 \%{ }^{a c}$ & $2.3 \%^{\mathrm{ab}}$ \\
\hline$\$ 6000-\$ 11,999$ & $5.8 \%{ }^{a b c}$ & $4.2 \%{ }^{b c}$ & $4.5 \%^{\mathrm{ac}}$ & $4.8 \%{ }^{\mathrm{ab}}$ \\
\hline$\$ 12,000-\$ 23,999$ & $12.4 \%{ }^{a b}$ & $11.3 \%^{\mathrm{c}}$ & $11.1 \%^{\mathrm{c}}$ & $12.6 \%{ }^{a b}$ \\
\hline$\$ 24,000-\$ 35,999$ & $11.3 \%{ }^{a b c}$ & $11.9 \%^{\mathrm{c}}$ & $11.6 \%^{\mathrm{c}}$ & $14.0 \%{ }^{\mathrm{ab}}$ \\
\hline$\$ 36,000-\$ 47,999$ & $9.4 \%{ }^{a b c}$ & $10.7 \%^{\mathrm{c}}$ & $10.8 \%^{\mathrm{c}}$ & $11.9 \%{ }^{a b}$ \\
\hline$\$ 48,000-\$ 59,999$ & $8.1 \%{ }^{a b c}$ & $9.8 \%{ }^{\mathrm{c}}$ & $9.8 \%{ }^{c}$ & $8.6 \%{ }^{\mathrm{ab}}$ \\
\hline$\$ 60,000-\$ 89,999$ & $12.9 \%{ }^{a b c}$ & $19.4 \%$ & $19.3 \%$ & $19.8 \%$ \\
\hline$\$ 90,000-\$ 119,999$ & $5.5 \%{ }^{a b c}$ & $12.3 \%^{b c}$ & $11.8 \%^{\mathrm{ac}}$ & $10.5 \%{ }^{a b}$ \\
\hline$\$ 120,000$ or More & $9.8 \%$ abc & $17.7 \%{ }^{\mathrm{bc}}$ & $16.5 \%{ }^{\mathrm{ac}}$ & $15.5 \%{ }^{a b}$ \\
\hline Missing/Don't Know & $22.1 \%{ }^{a b c}$ & $0.0 \%$ & $0.0 \%$ & $0.0 \%$ \\
\hline
\end{tabular}




\section{Notes:}

$\mathrm{a}=$ differs from CPS at $\mathrm{p}<0.05$

$\mathrm{b}=$ differs from ACS at $\mathrm{p}<0.05$

$\mathrm{c}=$ differs from NHIS at $\mathrm{p}<0.05$

Using t-tests for continuous variables and chi square for categorical variables.

$\dagger$ Gallup-Healthways is weighted to the following variables for age 18 and over non-group telephone households in the US, based on the CPS: age, race/ethnicity, education, gender, and region. The survey is not weighted to CPS targets for the percentage of households with children or annual household income.

$\S$ Missing incomes are imputed in the CPS, ACS, and NHIS surveys, but not in the Gallup-Healthways WBI. 
Table 3: Insurance Coverage Estimates in Gallup-Healthways Well-Being Index versus Other National Surveys (Calendar Year 2010)

\begin{tabular}{|c|c|c|c|c|c|}
\hline \multicolumn{6}{|c|}{ Panel A: Without Health Insurance Hierarchy } \\
\hline AGE AND COVERAGE & $\begin{array}{c}\text { Gallup- } \\
\text { Healthways }\end{array}$ & $\begin{array}{l}\text { (a) } \\
\text { CPS }\end{array}$ & $\begin{array}{c}\text { (b) } \\
\text { ACS }\end{array}$ & $\begin{array}{c}\text { (c) } \\
\text { NHIS }\end{array}$ & $\begin{array}{c}\text { (d) } \\
\text { BRFSS }\end{array}$ \\
\hline \multicolumn{6}{|l|}{ Ages 18-64 } \\
\hline -Uninsured & $19.7 \%^{\text {abcd }}$ & $21.8 \%{ }^{\mathrm{d}}$ & $21.8 \%{ }^{\mathrm{d}}$ & $22.1 \%{ }^{d}$ & $18.5 \%$ abc \\
\hline -ESI & $52.2 \%{ }^{a b c}$ & $60.1 \%{ }^{b c}$ & $58.8 \%^{\mathrm{ac}}$ & $57.8 \%{ }^{a b}$ & - \\
\hline -Military & $3.5 \%{ }^{a b c}$ & $3.8 \%{ }^{b c}$ & $2.5 \%^{\mathrm{a}}$ & $2.7 \%^{\mathrm{a}}$ & - \\
\hline -Medicare & $4.9 \%{ }^{a b c}$ & $3.8 \%{ }^{\mathrm{bc}}$ & $3.5 \%^{\mathrm{ac}}$ & $3.0 \%{ }^{a b}$ & - \\
\hline -Medicaid & $4.4 \%{ }^{a b c}$ & $9.9 \%^{b}$ & $10.6 \%^{\mathrm{ac}}$ & $9.6 \%^{b}$ & - \\
\hline -Other / Non-Group & $11.6 \%{ }^{a b c}$ & $7.6 \%{ }^{b c}$ & $9.7 \%{ }^{\mathrm{ac}}$ & $6.4 \%{ }^{a b}$ & - \\
\hline -Insured, but source unknown / refused $\dagger$ & $3.7 \%{ }^{a b c}$ & $0.0 \%{ }^{\mathrm{c}}$ & $0.0 \%^{\mathrm{c}}$ & $0.9 \%{ }^{\mathrm{ab}}$ & - \\
\hline \multicolumn{6}{|l|}{65 and Over } \\
\hline -Uninsured & $3.1 \%{ }^{a b c d}$ & $2.0 \%{ }^{b c}$ & $1.0 \%{ }^{\mathrm{ad}}$ & $1.1 \%{ }^{\mathrm{ad}}$ & $2.0 \%{ }^{b c}$ \\
\hline -ESI & $11.4 \% \%^{a b c}$ & $32.5 \%{ }^{b c}$ & $36.3 \%^{\mathrm{ac}}$ & $27.3 \%^{a b}$ & - \\
\hline -Military & $2.7 \%^{a b c}$ & $8.1 \%{ }^{b c}$ & $5.9 \%^{\mathrm{ac}}$ & $6.9 \%{ }^{a b}$ & - \\
\hline -Medicare & $67.1 \%{ }^{a b c}$ & $93.1 \%{ }^{b c}$ & $96.7 \%^{\mathrm{ac}}$ & $94.0 \%{ }^{a b}$ & - \\
\hline -Medicaid & $3.0 \%{ }^{a b c}$ & $9.2 \%^{b}$ & $15.9 \%^{\mathrm{ac}}$ & $8.7 \%^{b}$ & - \\
\hline -Other / Non-Group & $7.6 \%{ }^{a b c}$ & $28.8 \%^{b c}$ & $36.7 \%^{\mathrm{ac}}$ & $25.6 \%{ }^{a b}$ & - \\
\hline -Insured, but source unknown / refused $\dagger$ & $5.1 \%{ }^{a b c}$ & $0.0 \%{ }^{\mathrm{c}}$ & $0.0 \%^{\mathrm{c}}$ & $0.4 \%{ }^{a b}$ & - \\
\hline
\end{tabular}

Panel B: Using Health Insurance Hierarchy§

\begin{tabular}{|l|c|c|c|c|c|}
\hline AGE AND COVERAGE & $\begin{array}{c}\text { Gallup- } \\
\text { Healthways }\end{array}$ & $\begin{array}{c}\text { (a) } \\
\text { CPS }\end{array}$ & $\begin{array}{c}\text { (b) } \\
\text { ACS }\end{array}$ & $\begin{array}{c}\text { (c) } \\
\text { NHIS }\end{array}$ & $\begin{array}{c}\text { (d) } \\
\text { BRFSS }\end{array}$ \\
\hline Ages 18-64 & & & & & \\
\hline -Uninsured & $19.7 \%^{a b c d}$ & $21.8 \%^{\mathrm{d}}$ & $21.8 \%^{\mathrm{d}}$ & $22.1 \%^{\mathrm{d}}$ & $18.5 \%^{\mathrm{abc}}$ \\
\hline -ESI & $52.2 \%^{\mathrm{abc}}$ & $60.1 \%^{\mathrm{bc}}$ & $58.8 \%^{\mathrm{ac}}$ & $57.8 \%^{\mathrm{ab}}$ & - \\
\hline -Military & $3.5 \%^{\mathrm{abc}}$ & $1.8 \%^{\mathrm{bc}}$ & $1.6 \%^{\mathrm{ac}}$ & $2.1 \%^{\mathrm{ab}}$ & - \\
\hline -Medicare & $4.9 \%^{\mathrm{abc}}$ & $1.8 \%^{\mathrm{b}}$ & $1.3 \%^{\mathrm{ac}}$ & $1.7 \%^{\mathrm{b}}$ & - \\
\hline -Medicaid & $4.4 \%^{\mathrm{abc}}$ & $8.4 \%^{\mathrm{bc}}$ & $9.6 \%^{\mathrm{a}}$ & $9.4 \%^{\mathrm{a}}$ & - \\
\hline -Other / Non-Group & $11.6 \%^{\mathrm{abc}}$ & $4.5 \%^{\mathrm{bc}}$ & $6.5 \%^{\mathrm{ac}}$ & $5.7 \%^{\mathrm{ab}}$ & - \\
\hline -Insured, but source unknown / refused $\dagger$ & $3.8 \%^{\mathrm{abc}}$ & $0.0 \%^{\mathrm{c}}$ & $0.0 \%^{\mathrm{c}}$ & $0.9 \%^{\mathrm{ab}}$ & - \\
\hline & & & & & \\
\hline 65 and Over & & & & & \\
\hline -Uninsured & $3.1 \%^{\mathrm{abcd}}$ & $2.0 \%^{\mathrm{bc}}$ & $1.0 \%^{\mathrm{ad}}$ & $1.1 \%^{\mathrm{ad}}$ & $2.0 \%{ }^{\mathrm{bc}}$ \\
\hline -ESI & $11.4 \%^{\mathrm{abc}}$ & $4.1 \%^{\mathrm{bc}}$ & $1.9 \%^{\mathrm{ac}}$ & $2.8 \%^{\mathrm{ab}}$ & - \\
\hline -Military & $2.7 \%^{\mathrm{abc}}$ & $0.1 \%^{\mathrm{bc}}$ & $0.0 \%^{\mathrm{ac}}$ & $0.4 \%^{\mathrm{ab}}$ & - \\
\hline -Medicare & $67.1 \%^{\mathrm{abc}}$ & $93.1 \%^{\mathrm{bc}}$ & $96.7 \%^{\mathrm{ac}}$ & $94.0 \%^{\mathrm{ab}}$ & - \\
\hline -Medicaid & $3.0 \%^{\mathrm{abc}}$ & $0.1 \%^{\mathrm{bc}}$ & $0.0 \%^{\mathrm{ac}}$ & $0.8 \%^{\mathrm{ab}}$ & - \\
\hline -Other / Non-Group & $7.6 \%^{\mathrm{abc}}$ & $0.5 \%^{\mathrm{b}}$ & $0.3 \%^{\mathrm{ac}}$ & $0.5 \%^{\mathrm{b}}$ & - \\
\hline -Insured, but source unknown / refused $\dagger$ & $5.1 \%^{\mathrm{abc}}$ & $0 . \%^{\mathrm{b}}$ & $0.0 \%^{\mathrm{c}}$ & $0.4 \%^{\mathrm{ab}}$ & - \\
\hline
\end{tabular}

Notes: 
$\mathrm{a}=$ differs from CPS at $\mathrm{p}<0.05$

$\mathrm{b}=$ differs from ACS at $\mathrm{p}<0.05$

$c=$ differs from NHIS at $p<0.05$

$\mathrm{d}=$ differs from BRFSS at $\mathrm{p}<0.05$

Using chi square tests for categorical variables

$\dagger$ This item in the NHIS means no insurance information was provided.

For the NHIS, we included "other public coverage" and "other government coverage" in Medicaid and CHIP, and "all private insurance not associated with employment or a union" and "other private coverage" in our "other/nongroup" category.

In analysis of the CPS, we describe the data as based on the year to which the questions were in reference. While some prior research indicates that CPS insurance estimates more closely resemble point-in-time estimates than 'full prior year' estimates (Swartz 1986), other research indicates that respondents do understand that the questions specifically refer to the previous year (Klerman, Davern et al. 2009), and this is likely also the case for income. $\S$ For adults 18-64, the hierarchy was: 1) ESI, 2) Medicaid/CHIP, 3) Medicare, 4) Military coverage, 5) Other or Non-Group Coverage, 6) Uninsured. For elderly adults, Medicare was first in the hierarchy, with the remaining order unchanged. 
Table 4: Estimates of Access to Care and Health Status in Gallup-Healthways Well-Being Index versus Other National Surveys

Panel A: Access to Care Measures (Calendar Year 2009)

\begin{tabular}{|l|c|c|c|c|}
\hline OUTCOME & $\begin{array}{c}\text { Gallup- } \\
\text { Healthways }\end{array}$ & $\begin{array}{c}\text { (a) } \\
\text { BRFSS }\end{array}$ & $\begin{array}{c}\text { (b) } \\
\text { NHIS }\end{array}$ & $\begin{array}{c}\text { (c) } \\
\text { MEPS }\end{array}$ \\
\hline $\begin{array}{l}\text { Has a personal doctor / } \\
\text { usual source of care }\end{array}$ & $80.6 \%^{\mathrm{b}}$ & $81.0 \%{ }^{\mathrm{b}}$ & $84.5 \%^{\mathrm{a}}$ & - \\
\hline $\begin{array}{l}\text { Cost-related barriers: } \\
\text { 'Not enough money for } \\
\text { healthcare' (Gallup); } \\
\text { 'Delayed or deferred care } \\
\text { due to cost' (Others) }\end{array}$ & $18.6 \%^{\mathrm{abc}}$ & $14.9 \%^{\mathrm{bc}}$ & $17.6 \%^{\mathrm{ac}}$ & $9.0 \%{ }^{\mathrm{ab}}$ \\
\hline
\end{tabular}

Panel B: Health Status Measures (Calendar Year 2009)

\begin{tabular}{|c|c|c|c|c|c|}
\hline OUTCOME & $\begin{array}{c}\text { Gallup- } \\
\text { Healthways }\end{array}$ & $\begin{array}{c}\text { (a) } \\
\text { BRFSS }\end{array}$ & $\begin{array}{c}\text { (b) } \\
\text { NHIS }\end{array}$ & $\begin{array}{c}\text { (c) } \\
\text { MEPS }\end{array}$ & $\begin{array}{c}\text { (d) } \\
\text { CPS }\end{array}$ \\
\hline \multicolumn{6}{|l|}{ Self-Reported Health } \\
\hline -Excellent & $20.8 \%{ }^{\text {bcd }}$ & $20.8 \%^{\text {bcd }}$ & $29.0 \%{ }^{\text {acd }}$ & $27.4 \%{ }^{\text {abd }}$ & $26.0 \%^{\mathrm{abc}}$ \\
\hline -Very Good & $29.4 \%{ }^{\text {abcd }}$ & $32.8 \%$ bcd & $31.6 \%^{\mathrm{a}}$ & $31.8 \%^{\mathrm{a}}$ & $31.2 \%^{\mathrm{a}}$ \\
\hline -Good & $29.3 \%^{\text {abcd }}$ & $30.1 \%{ }^{\text {bcd }}$ & $26.8 \%^{\text {ad }}$ & $26.6 \%{ }^{\text {ad }}$ & $28.1 \%{ }^{\mathrm{abc}}$ \\
\hline -Fair & $14.8 \%^{\text {abcd }}$ & $11.8 \%{ }^{\text {bcd }}$ & $9.4 \%{ }^{\text {acd }}$ & $10.6 \%$ ab & $10.3 \%^{\mathrm{ab}}$ \\
\hline -Poor & $5.6 \%{ }^{\text {abcd }}$ & $4.3 \%$ bcd & $3.1 \%$ acd & $3.6 \%$ abd & $4.4 \%{ }^{a b c}$ \\
\hline -Don’t Know / Refused & $0.1 \%{ }^{\text {abcd }}$ & $0.4 \%{ }^{\text {bcd }}$ & $0.2 \%{ }^{\text {acd }}$ & $0.0 \%{ }^{\text {abd }}$ & $0.0 \%{ }^{a b c}$ \\
\hline \multicolumn{6}{|l|}{ Been Diagnosed with: } \\
\hline High Blood Pressure & $30.6 \%^{\mathrm{ac}}$ & $29.4 \%{ }^{b c}$ & $31.2 \%^{\mathrm{ac}}$ & $32.5 \%{ }^{a b}$ & - \\
\hline High Cholesterol & $27.6 \%^{\mathrm{ac}}$ & $38.1 \%^{\mathrm{c}}$ & - & $31.2 \%{ }^{a}$ & - \\
\hline Diabetes & $11.1 \%{ }^{a b c}$ & $9.1 \%^{\mathrm{c}}$ & $9.5 \%^{\mathrm{c}}$ & $8.5 \%^{a b}$ & - \\
\hline Depression $\dagger$ & $17.4 \%^{a c}$ & $8.0 \%^{\mathrm{c}}$ & - & $24.6 \%^{\mathrm{a}}$ & - \\
\hline Heart Attack & $4.6 \%{ }^{a b c}$ & $4.0 \%$ & $3.8 \%$ & $3.9 \%$ & - \\
\hline Asthma & $11.3 \%^{\mathrm{abc}}$ & $13.4 \%^{\mathrm{c}}$ & $13.3 \%^{\mathrm{c}}$ & $9.0 \%{ }^{\mathrm{ab}}$ & - \\
\hline Cancer & $7.2 \%{ }^{a b c}$ & $9.6 \% \%^{c}$ & $9.3 \%^{\mathrm{c}}$ & $10.2 \%{ }^{a b}$ & - \\
\hline
\end{tabular}

\section{Notes:}

$\mathrm{a}=$ differs from BRFSS at $\mathrm{p}<0.05$

$\mathrm{b}=$ differs from NHIS at $\mathrm{p}<0.05$

$\mathrm{c}=$ differs from MEPS at $\mathrm{p}<0.05$

$\mathrm{d}=$ differs from CPS at $\mathrm{p}<0.05$

Using chi square tests for categorical variables.

$\dagger$ This item in the MEPS measured the \% of adults reporting that they "felt sad or depressed at least several days in the past 2 weeks," and over the past 30 days in the BRFSS. All other questions took the form, "Have you ever been diagnosed with..." 
Figure 1: Percentage of Adults (18-64) without Health Insurance in

Gallup-Healthways Survey and Three Other Surveys, 2008-2011

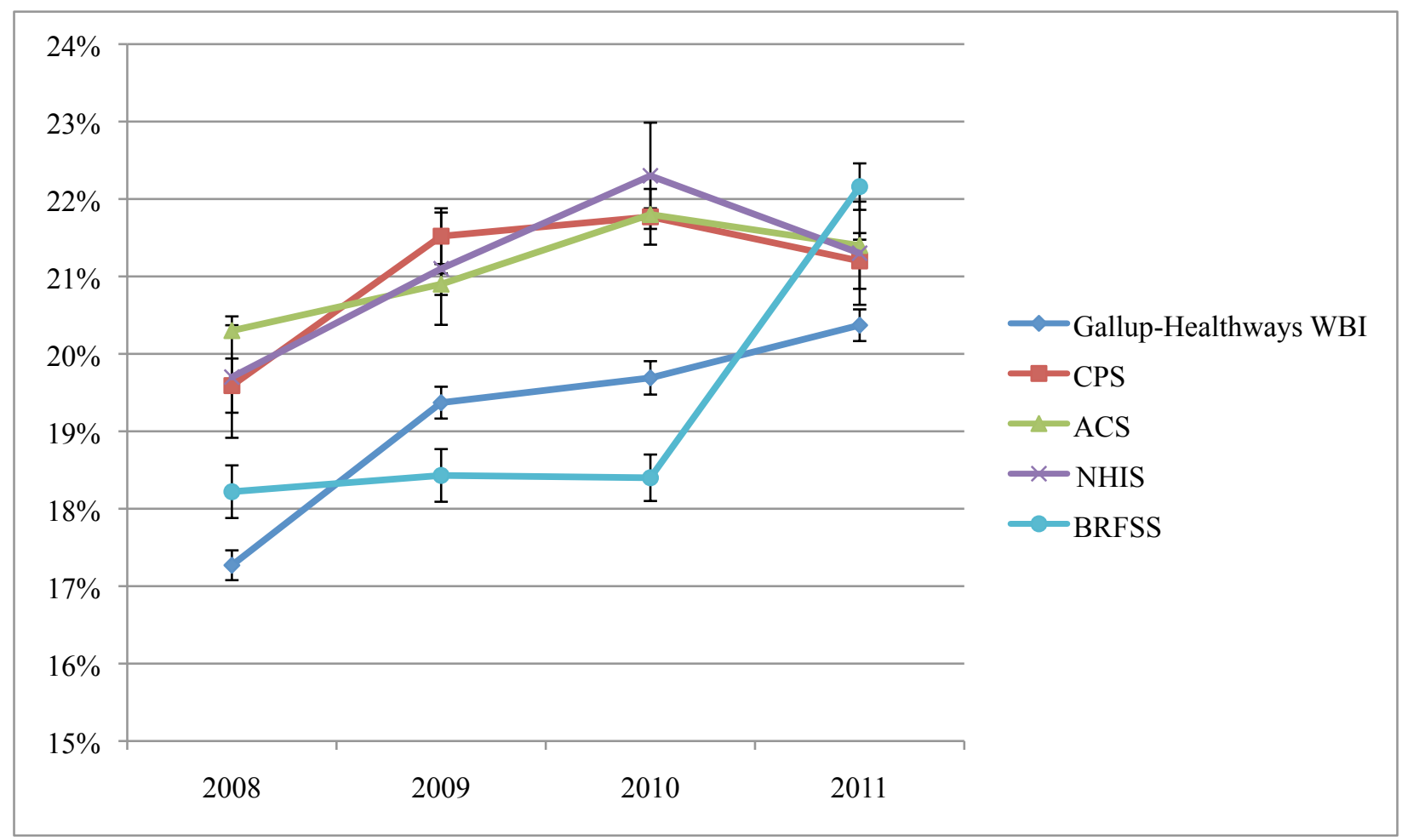

Notes:

ACS and NHIS are point-in-time estimates of the uninsured. CPS explicitly asks about coverage over the prior year, though previous research has documented that the CPS uninsured rate tracks more closely with point-in-time estimates from other surveys (Swartz, 1986). 


\section{Supplemental Appendix}

\section{Recent Methodological Changes in the Gallup WBI:}

Sampling: Prior to 2012, each daily sample in the WBI contained 1,000 individuals, and included a minimum quota of 400 cell phone respondents and 600 landline respondents, with additional stratification among landline respondents by region. In 2012, Gallup announced a change to its methodology to increase the proportion of cell phone participants based on shifts in communication behavior and habits of those being interviewed (Easley 2012). The survey also reduced the number of respondents answering health-related questions from 1,000 to 500 daily in 2013. Both before and after these changes, landline respondents are chosen at random within each household based on which member had the most recent birthday.

Weighting: Prior to 2012, estimates were weighted to targets for region, age, gender, race, ethnicity, education, number of adults in the landline household, and telephone status percent based on the Current Population Survey (CPS) figures for non-institutionalized adults aged 18 and older living in U.S. telephone households. For this reason, we do not expect the GallupHealthways population demographics in Table 2 to precisely match those for all adults in the CPS. Since 2012, weighting has been targeted to the full U.S. population in the CPS, not just telephone households. With the inclusion of the cell-phone-only households and the Spanish language interviews, $98 \%$ of the adult population is eligible for participation in the sample. Data can be summarized at the state, congressional district, and Metropolitan Statistical Area (MSA) levels, with weights specific to Census-based demographic targets at each level. 
Surveys

AGE: Open ended

RACE:

Are you of Hispanic, Latino, or Spanish origin - such as Mexican, Puerto Rican, Cuban, or other Spanish origin?

Next, I am going to read you a list of racial groups. As I read each one, please tell me whether you are -- or are not -- a member of that racial group. You may consider yourself to be a member of more than one racial group.

White

Black or African-American

Asian

American Indian or Alaska Native

Native Hawaiian or other Pacific Islander

\section{EDUCATION:}

What is your highest completed level of education?

01 Less than high school diploma

02 High school degree or diploma

03 Technical/Vocational school

04 Some college

05 College graduate

06 Post graduate work or degree

$07 \quad$ (DK)

08 (Refused) 
INCOME:

What is your total MONTHLY household income, before taxes? Please include income from wages and salaries, remittances from family members living elsewhere, farming, and all other sources. (Open ended and code)

$\begin{array}{ll}01 & \text { Under } \$ 60 \\ 02 & \$ 60 \text { to } \$ 499 \\ 03 & \$ 500 \text { to } \$ 999 \\ 04 & \$ 1,000 \text { to } \$ 1,999 \\ 05 & \$ 2,000 \text { to } \$ 2,999 \\ 06 & \$ 3,000 \text { to } \$ 3,999 \\ 07 & \$ 4,000 \text { to } \$ 4,999 \\ 08 & \$ 5,000 \text { to } \$ 7,499 \\ 09 & \$ 7,500 \text { to } \$ 9,999 \\ 10 & \$ 10,000 \text { to } \$ 14,999 \\ 11 & \$ 15,000 \text { to } \$ 19,999 \\ 12 & \$ 20,000 \text { and over } \\ 98 & \text { (DK) } \\ 99 & \text { (Refused) }\end{array}$

Skip: (If code 98 or 99, Continue; Otherwise, Skip)

Is your total MONTHLY household income before taxes $\$ 4,000$ or more, or is it less than $\$ 4,000$ ?

(Interviewer:

(If under, ask:) Is it over or under $\$ 3,000$ ?

(If under, ask:) Is it over or under $\$ 2,000$ ?

(If under, ask:) Is it over or under $\$ 1,000$ ?

(If under, ask:) Is it over or under $\$ 500$ ?

(If under, ask:) Is it over or under $\$ 60$ ?)

(Interviewer:

(If over, ask:) Is it over or under $\$ 5,000$ ?

(If over, ask:) Is it over or under $\$ 7,500$ ?

(If over, ask:) Is it over or under $\$ 10,000$ ?

(If over, ask:) Is it over or under $\$ 15,000$ ?

(If over, ask:) Is it over or under $\$ 20,000$ ?)

\section{CHILDREN IN HOUSEHOLD:}

How many children, under the age of 18 , are living in your household? (Open ended) 


\section{HEALTH INSURANCE:}

Do you have health insurance coverage?

1 Yes

2 No

$3 \quad(\mathrm{DK})$

$4 \quad$ (Refused)

Is your primary health insurance coverage through an employer or union, through Medicare, Medicaid, military or Veteran's coverage, or something else?

1 Employer or union

2 Medicare

3 Medicaid

$4 \quad$ Military or Veteran's

5 Something else

8 (DK)

$9 \quad$ (Refused)

HEALTH STATUS: Would you say your own health, in general, is:

$\begin{array}{ll}1 & \text { Excellent } \\ 2 & \text { Very good } \\ 3 & \text { Good } \\ 4 & \text { Fair, OR } \\ 5 & \text { Poor } \\ 8 & \text { (DK) } \\ 9 & \text { (Refused) }\end{array}$

Have you ever been told by a physician or nurse that you have any of the following, or not?

High blood pressure

High cholesterol

Diabetes

Depression

Heart attack

Asthma

Cancer

Do you have a personal doctor?

$\begin{array}{ll}1 & \text { Yes } \\ 2 & \text { No } \\ 3 & \text { (DK) } \\ 4 & \text { (Refused) }\end{array}$




\section{Appendix Figure 1:}

Percentage of Adults (18-64) without Health Insurance, by State, in Gallup-Healthways Well-Being Index versus the American Community Survey (ACS), 2010

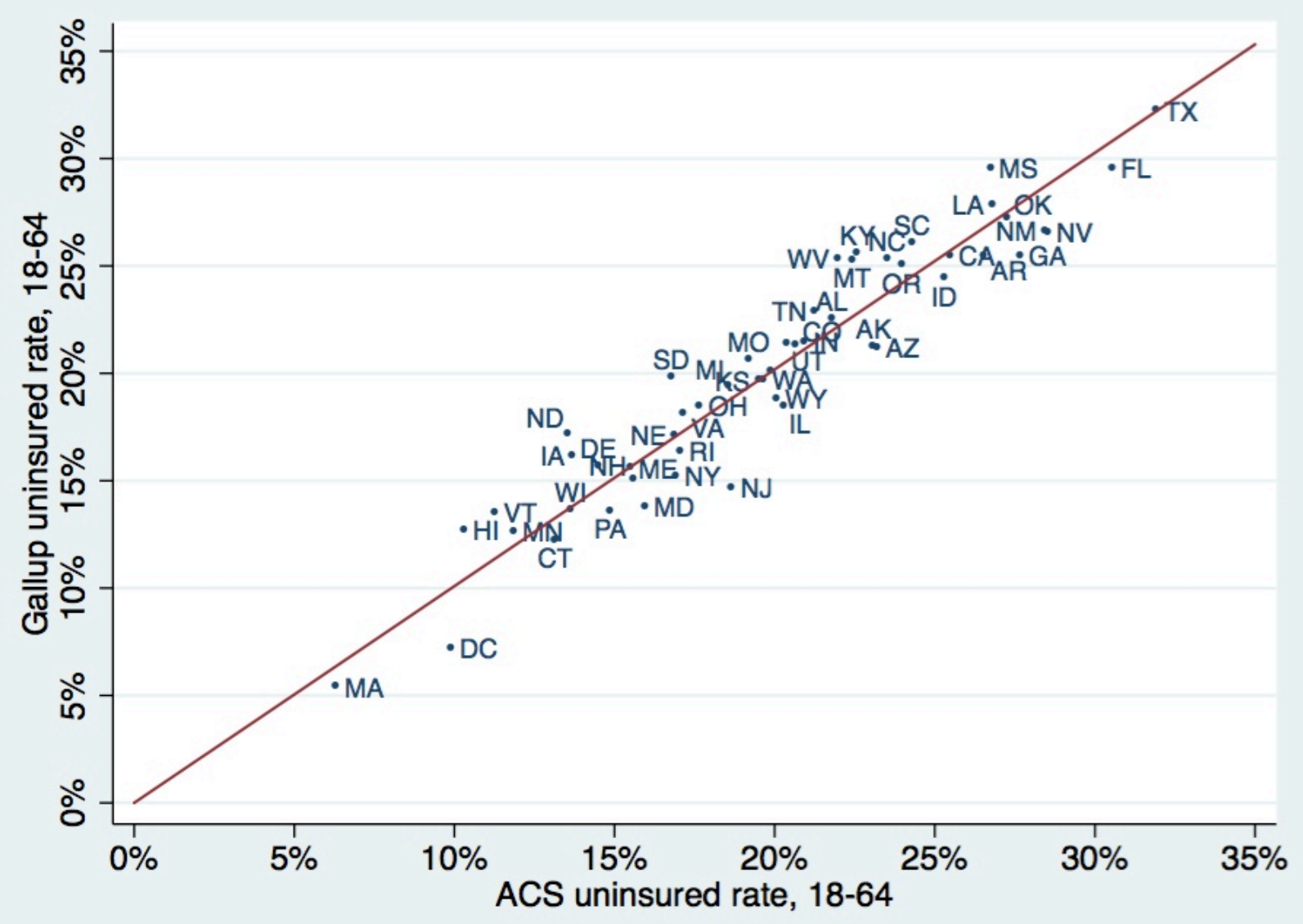

Note: Red line shows the fitted regression line relating the state estimates from the two data sources. 
Appendix Figure 2:

Percentage of Adults (18-64) without Health Insurance, by State, in Gallup-Healthways Well-Being Index versus the Current Population Survey (CPS), 2010

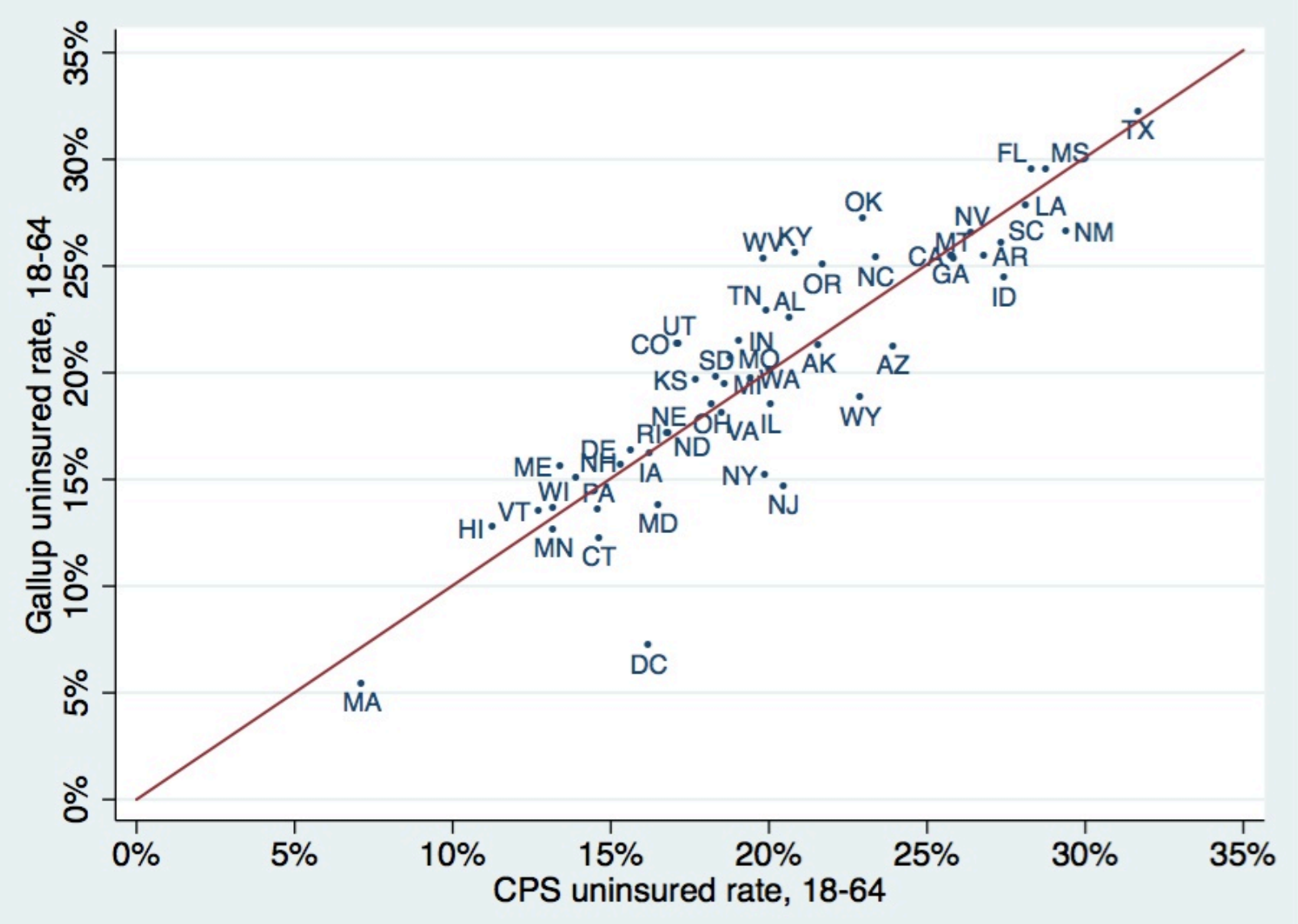

Note: Red line shows the fitted regression line relating the state estimates from the two data sources. 


\section{Appendix Figure 3:}

Percentage of Adults (18-64) with Medicaid, by State, in Gallup-Healthways Well-Being Index versus the American Community Survey (ACS), 2010

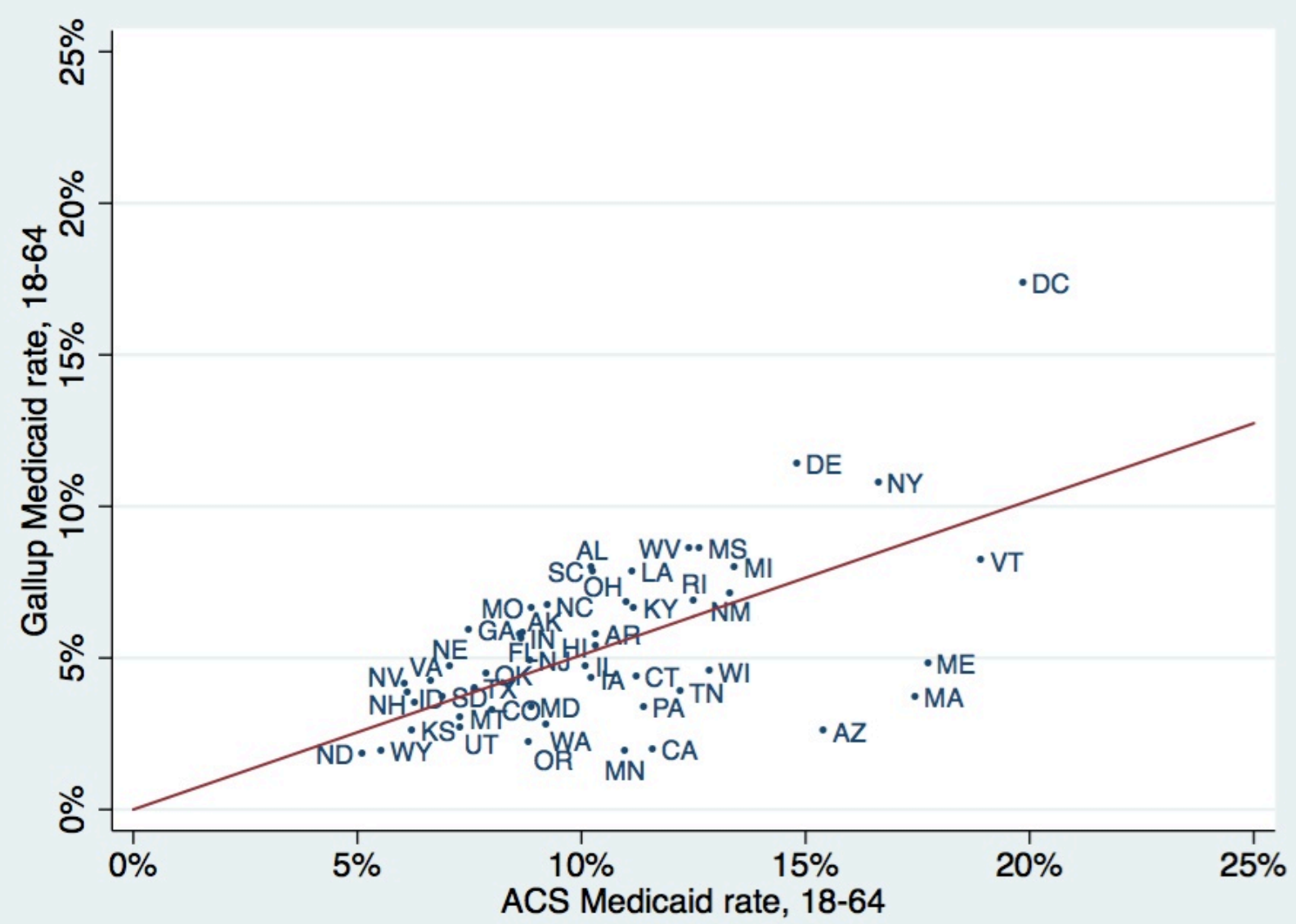

Note: Red line shows the fitted regression line relating the state estimates from the two data sources. 
Appendix Figure 4:

Percentage of Adults (18-64) with Medicaid, by State, in Gallup-Healthways Well-Being Index versus the Current Population Survey (CPS), 2010

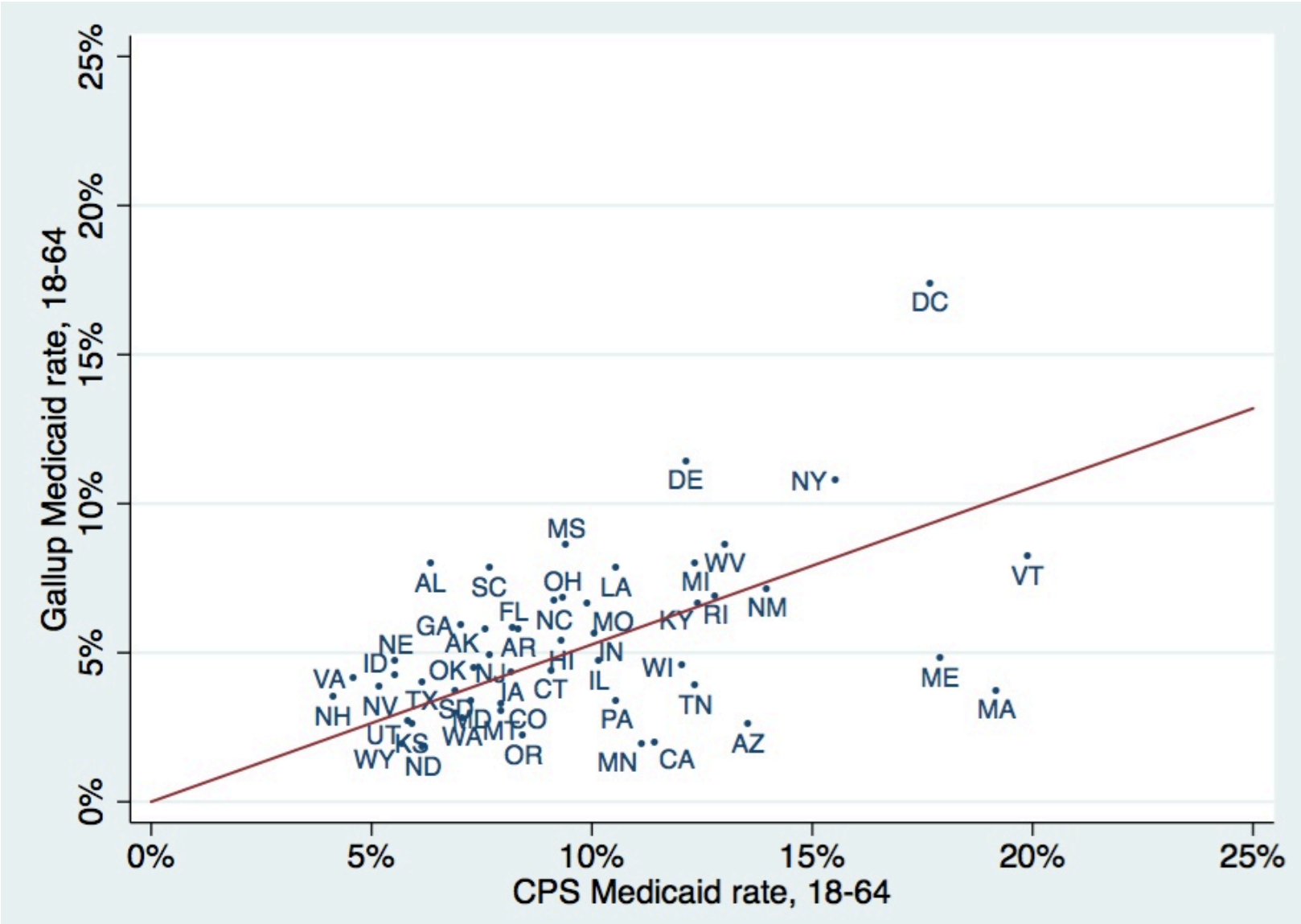

Note: Red line shows the fitted regression line relating the state estimates from the two data sources. 
Appendix Table 1:

Income Distribution After Imputation for Missing Values in Gallup-Healthways Well-Being Index, 2010

\begin{tabular}{|l|c|c|c|}
\hline Annual Household Income & $\begin{array}{c}\text { Reported } \\
\text { Income }\end{array}$ & $\begin{array}{c}\text { Imputed Values } \\
\text { for Missing } \\
\text { Income }\end{array}$ & $\begin{array}{c}\text { Full Gallup } \\
\text { Sample, } \\
\text { Including } \\
\text { Imputed Values }\end{array}$ \\
\hline$<\$ \mathbf{6 0 0 0}$ & $3.6 \%$ & $1.3 \%$ & $3.1 \%$ \\
\hline $\mathbf{\$ 6 0 0 0 - \$ 1 1 , 9 9 9}$ & $7.4 \%$ & $2.2 \%$ & $6.2 \%$ \\
\hline $\mathbf{\$ 1 2 , 0 0 0 - \$ 2 3 , 9 9 9}$ & $15.9 \%$ & $9.9 \%$ & $14.6 \%$ \\
\hline $\mathbf{\$ 2 4 , 0 0 0 - \$ 3 5 , 9 9 9}$ & $14.5 \%$ & $15.3 \%$ & $14.7 \%$ \\
\hline $\mathbf{\$ 3 6 , 0 0 0 - \$ 4 7 , 9 9 9}$ & $12.0 \%$ & $18.8 \%$ & $13.5 \%$ \\
\hline $\mathbf{\$ 4 8 , 0 0 0 - \$ 5 9 , 9 9 9}$ & $10.4 \%$ & $17.6 \%$ & $12.0 \%$ \\
\hline $\mathbf{\$ 6 0 , 0 0 0 - \$ 8 9 , 9 9 9}$ & $16.5 \%$ & $28.1 \%$ & $19.1 \%$ \\
\hline $\mathbf{\$ 9 0 , 0 0 0 - \$ 1 1 9 , 9 9 9}$ & $7.1 \%$ & $6.8 \%$ & $7.0 \%$ \\
\hline $\mathbf{\$ 1 2 0 , 0 0 0}$ or More & $12.6 \%$ & $0.0 \%$ & $9.8 \%$ \\
\hline & & & \\
\hline Missing/Don't Know & $0 \%$ & $100 \%$ & $22.0 \%$ \\
\hline Mean Income & $\$ 55,415$ & $\$ 51,284$ & $\$ 54,502$ \\
\hline
\end{tabular}

